\title{
O DUPLO ASPECTO EDUCATIVO DOS JOGOS DIGITAIS COMO VIVÊNCIA DE LAZER DE CRIANÇAS E JOVENS
}

Recebido em: 18/05/2020

Aprovado em: 20/01/2021

Licença:@) (1) @

\author{
Vinicius Augusto do Nascimento Monteiro ${ }^{1}$ \\ Silvan Menezes dos Santos ${ }^{2}$ \\ Universidade Federal de Mato Grosso do Sul (UFMS) \\ Campo Grande - MS - Brasil
}

RESUMO: Os jogos digitais incorporaram-se nas vivências de lazer de crianças e jovens. São importantes mediadores da cultura contemporânea e apresentam indícios de potencial educativo nas experiências lúdicas que produzem. Nesse sentido, o objetivo do estudo foi compreender por quais vias ocorre a educação para os games e identificar expressões de aprendizagem por meio da vivência dos jogos digitais. Aplicamos um questionário com 21 alunos e 14 alunas de $6^{\circ}$ ano do ensino fundamental, com faixa etária entre 10 e 14 anos. Identificamos a mediação familiar e domiciliar no princípio da educação para os jogos digitais, bem como a presença dos círculos de amizades e das tecnologias nesse processo. Neste ponto chamamos atenção para a ausência da escola, da Educação Física e, principalmente, do Estado como instituições e ambiências mediadoras da formação cultural infanto-juvenil para, com e sobre o universo lúdico digital.

PALAVRAS-CHAVE: Jogos Digitais. Cultura Digital. Tecnologias.

\section{THE DOUBLE EDUCATIONAL ASPECT OF DIGITAL GAMES AS A LEISURE EXPERIENCE FOR CHILDREN AND YOUNG PEOPLE}

ABSTRACT: The digital games have been incorporated into the leisure experiences of children and young people. They are important mediators of contemporary culture and show signs of educational potential in the playful experiences they produce. In this sense, the objective of the study was to understand the ways in which education for games occurs and to identify expressions of learning through the games experience. We applied a questionnaire with 21 boys and 14 girls from the 6th year of elementary school, aged between 10 and 14 years old. We identified family and home mediation in the principle of education for games, as well as the presence of circles of friends and technologies in this process. At this point, we call attention to the absence schools,

\footnotetext{
${ }^{1}$ Graduado em Educação Física Licenciatura pela Universidade Federal de Mato Grosso do Sul. Bolsista do Programa de Educação Tutorial - PET Educação Física (2017-2019). Atualmente, é membro do Remix - Observatório de mídias, tecnologias digitais e práticas corporais da Universidade Federal de Mato Grosso do Sul.

2 Professor Adjunto dos cursos de Educação Física da Faculdade de Educação da Universidade Federal de Mato Grosso do Sul. Membro do Laboratório e Observatório da Mídia Esportiva (LaboMídia) e coordenador do Remix - Observatório de mídias, tecnologias digitais e práticas corporais.
} 
Physical Education and, mainly, the State as institutions and environments that mediate children's and youth cultural education for, with and about the digital ludic universe.

KEYWORDS: Games. Digital Culture. Technologies.

\section{Introdução}

A sociedade passa, dia após dia, por adaptações aos avanços tecnológicos do universo eletrônico e da informática. A vida hiperconectada tem provocado alterações, principalmente, em nossas visões de mundo e percepções da realidade. É o denominado contexto onlife $e^{3}$, no qual as tecnologias digitais de informação e comunicação (TDICs) têm influenciado, sobretudo por meio do Big Data e da infoesfera, em dimensões políticas, econômicas e sociais tais como as noções de controle e complexidade, de espaço público e privado (THE ONLIFE INITIATIVE, 2015).

A interferência direta ou indireta das TDICs nos modos de viver atualmente é inegável. São mutações culturais diversas, que reconfiguraram tempos e espaços sociais, expandindo-os, tornando-os perduráveis, desenvolvendo assim um novo sensorium (RINCÓN, 2018; 2019). "Nossas ações, percepções, intenções, nossa moralidade e corporeidade em síntese são modeladas pelas tecnologias em geral e pelas TICs em particular" ${ }^{4}$ (THE ONLIFE INITIATIVE, 2015, p. 12). Ou seja, nossos modos de ser, estar e compreender o mundo modificaram-se, bem como têm surgido permanentemente novos códigos e símbolos que reconfiguram a cultura humana. Um exemplo de questão

\footnotetext{
${ }^{3}$ Neste texto acompanhamos a definição de "contexto onlife" do manifesto publicado, originalmente, em 2015, por um conjunto de pesquisadores/as organizados/as na chamada "The Onlife Initiative". Entendese que a condição humana de existência está sendo diretamente impactada pelo desenvolvimento e usos indistintos das tecnologias digitais de informação e comunicação, pois para além de ferramentas elas funcionam como forças ambientais que afetam e modificam a vida cotidiana. Para o grupo, este fenômeno produziu um contexto modificado das nossas autopercepções, dos nossos modos de socialização, das concepções de realidade e da forma como interagimos com ela. Em especial, as principais transformações representativas do contexto onlife seriam o desvanecimento dos limites entre realidade e virtualidade, a dificuldade de distinção entre humano, máquina e natureza, a reversão da escassez de informação para a sua abundância, e, por fim, a transição da primazia das coisas para o primado das interações (THE ONLIFE INITIATIVE, 2015).

4 No original em inglês: “[...] our actions, perceptions, intentions, morality, even corporality are interwoven with technologies in general, and ICTs in particular".
} 
insurgente, manifesta neste contexto, é como as pessoas e diferentes povos têm concebido os seus tempos livres? Como têm se configurado os passatempos dos grupos sociais nesta era hiperconectada? Como este contexto onlife penetra e interfere no jogar/brincar das infâncias?

Os impactos do contexto onlife não são somente em aspectos intersubjetivos ou intangíveis da sociedade, como a sobrecarga cognitiva, a distração e a amnésia provocadas pela abundância de informação (THE ONLIFE INITIATIVE, 2015). Manifestações corporais básicas e complexas do cotidiano foram também permeadas. Atividades múltiplas da esfera produtiva e não produtiva da modernidade são perpassadas pelas TDICs. O trabalho, os afazeres domésticos, os cuidados de si, as práticas corporais, como os esportes e as atividades físicas e, não diferentemente, o lazer, são espaços-tempos onde e quando se pode perceber interferências do modo de vida hiperconectado. O home office ou o trabalho remoto, os aplicativos de personalização e monitoramento de treinos físico-esportivos, bem como a ocupação dos tempos livres com jogos digitais e redes sociais de diferentes finalidades (acadêmicas, de relacionamento, etc.), são expressões das intermediações culturais do contexto onlife.

Schwartz (2003), ainda no início do século XXI, chamava atenção para a manifestação do que denominou como conteúdos/interesses virtuais no âmbito do lazer. Ela propôs a adição desse fenômeno junto aos interesses físicos, manuais, estéticos, intelectuais e sociais, descritos e categorizados por Dumazedier (1979) como interesses culturais do lazer, bem como aos turísticos, dissertados por Camargo (1998). Naquele momento, segundo a autora, entendia-se que a utilização da mídia virtual poderia proporcionar uma nova visão aos conceitos e valores do lazer, ampliando as possibilidades no que se refere aos tempos e espaços dessa dimensão da vida (SCHWARTZ, 2003). Embora seja fundamental considerar novos interesses do lazer 
com a chegada da era digital, Schwartz (2003) restringe a definição de virtual, naquele momento, ao suporte/instrumento utilizado para as ações dos sujeitos. É compreensível, pois na ocasião ainda tateávamos o contexto digital e tecnológico emergente. Atualmente, sobretudo por conta do contexto onlife como descrito, torna-se limitado aplicar tal conceito, pois há dificuldades em delimitar as fronteiras entre online e offline, entre real e virtual, por exemplo. Contudo, ainda que não seja exatamente o foco deste trabalho estabelecer nova terminologia para tal, é premente analisarmos, pensarmos e refletirmos os interesses culturais do lazer manifestos no contexto tecnológico onlife.

Atualmente, navegar na internet, por exemplo, é a segunda atividade mais buscada para preencher os tempos de lazer dos brasileiros e brasileiras, seja em zonas urbanas ou rurais, ficando atrás apenas do hábito de assistir à TV (GRUBER; STOPPA, 2017). Cerca de 59,8\% da população do país utiliza a internet como opção de lazer e destes, segundo Gruber e Stoppa (2017), 26,7\% utilizam-na para acessar conteúdos físico-esportivos, 18,5\% para atividades sociais, 9,5\% para conteúdos artísticos, 7,4\% para atividades intelectuais, $7 \%$ para o ócio, 5,1\% acessam conteúdo turístico e 1,4\% para atividades manuais.

Os jogos digitais ${ }^{5}$, juntamente com as interações via redes sociais, são dois exemplos das incontáveis formas de expressão do lazer na ambiência tecnológica e digital. Estes jogos, inclusive, são alvo de grande atenção da sociedade no século XXI,

\footnotetext{
${ }^{5}$ Neste texto adotaremos a expressão jogos digitais para nos referirmos ao fenômeno, sabendo que comumente utiliza-se como sinônimo de games, videogames, jogos eletrônicos e outros termos, pois partimos da premissa que o seu conceito é dinâmico e evolui assim como as plataformas e ambientes virtuais nos quais ele se encontra (CRUZ JUNIOR, 2017a). Acompanhamos a definição de Cruz Junior (2017), para quem os jogos digitais são manifestações transmidiáticas, que transitam por diferentes recursos, instrumentos e plataformas, e se diferenciam dos jogos clássicos, sobretudo, na estrutura e aplicação das regras, pois estas são criadas e geridas pelo próprio computador, na diluição das noções de resultado final, considerando que o status de vencer ou perder é muitas das vezes indefinidos, na ideia de finais abertos, com jogos que nunca dispõem de um fim, e no grande espaço que se tem para a imaginação de quem joga.
} 
pois têm apresentado profunda e veloz evolução técnica e comercial (CRUZ JUNIOR, 2017a). Assim, eles têm atraído a juventude e se configurado como expressão potencial dos espaços e tempos lúdicos desse grupo social (CRUZ JUNIOR; BUNGESTAB, 2018). Eles permitem que crianças e jovens expressem o brincar e o se movimentar de dentro das suas casas, nos seus celulares. Entretanto, mesmo com a onipresença das tecnologias e da cultura digital nas vidas e nos desenvolvimentos das crianças no contexto onlife, tem-se identificado que os jogos digitais não necessariamente estão acima dos jogos tradicionais e esportivos como os mais buscados e praticados por elas (WIGGERS; OLIVEIRA; FERREIRA, 2018; FERNANDES et al., 2016).

O contato contínuo dos jovens e crianças ${ }^{6}$ com os jogos digitais e as mídias digitais em suas vidas, e a extensa preocupação social com tal situação, tem provocado o desenvolvimento de proposições para se pensar e agir educativamente para com as tecnologias e a cultura digital (FANTIN, 2006; 2015; MIRANDA; FANTIN, 2018). Basicamente, tem-se proposto a mobilização de estratégias didático-pedagógicas baseadas nas três dimensões da mídia-educação, que pressupõe a educação para, com e através das mídias, ou seja, tratando-as como objeto de estudo, como instrumento educacional e como meio de criação e produção de conhecimento.

Existem também reflexões e perspectivas específicas para o trabalho com jogos digitais e mídias na área da Educação Física. Algumas delas possuem foco na Educação Física escolar (SOUZA JUNIOR; LISBOA; COSTA, 2019; COSTA, 2016; PIRES; LAZZAROTTI FILHO; LISBÔA, 2012; COSTA; BETTI, 2006), e outras na atuação na área do lazer (CRUZ JUNIOR; BUNGENSTAB, 2018; CRUZ JUNIOR, 2017c; STOPPA et al., 2016).

\footnotetext{
${ }^{6}$ Importante destacar que neste trabalho optamos por não adentrar nas especificidades das definições de juventudes, infâncias, jovens ou crianças, e utilizamos tais termos de modo generalista, inclusive sem fazer diferenciações ao nos referirmos aos interlocutores de diferentes faixas etárias, pois as discussões e peculiaridades específicas destes fenômenos complexos e relevantes contemporaneamente não eram o foco do presente estudo.
} 
As proposições no campo da Educação Física escolar têm acompanhado, fortemente, a perspectiva mídia-educativa supracitada do campo da Educação. A ideia tem sido trabalhar fenômenos da cultura corporal de movimento que estão em interface com a cultura midiática (PIRES; LAZZAROTTI FILHO; LISBÔA, 2012), como por exemplo, o jornalismo esportivo. O estudo de Mendes e Pires (2009), por sua vez, apresenta o desenvolvimento de estratégias didático-pedagógicas que proporcionam uma leitura crítica da cobertura midiático-esportiva por parte de alunos/as e, posteriormente, provocam a elaboração de roteiros e mecanismos técnicos de criação de outras formas de cobrir o esporte jornalisticamente.

A perspectiva de trabalho pedagógico da Educação Física para com os jogos digitais segue linha semelhante à da abordagem mídia-educativa. A proposta, em diferentes situações, tem sido promover a ressignificação, atualização ou remixagem corporal de dinâmicas, regras, espaços e tempos destes fenômenos lúdicos em ambientes escolares, de modo a promover análises, releituras e recriações críticas destes jogos. Costa e Betti (2006), por exemplo, realizaram experiência com o Quadribol, jogo digital inspirado no filme Harry Potter. Silva et al. (2020), por sua vez, também promoveram uma experiência nesta linha com o jogo Free Fire.

No campo do lazer propriamente dito, ou seja, da animação sociocultural, as proposições de trabalho para com os jogos digitais têm adquirido consistência e demonstrado amplo potencial, mas ainda planam no universo teórico. Cruz Junior (2017c), por exemplo, chama atenção, em síntese, para as potencialidades lúdicas e possibilidades educativas do Pokemon Go, jogo de realidade aumentada. O autor destaca a promoção da apropriação de espaços urbanos, históricos e turísticos, por parte dos seus jogadores ao circularem pelas cidades, bem como a produção de outras formas de sociabilidade e movimentação a partir da dinâmica do referido jogo. Ele trata todos 
estes como elementos que podem ser observados e mediados pela Educação Física na sua atuação nos campos formais e não formais de educação.

A Base Nacional Comum Curricular (BNCC), documento de referência em vigência para a educação brasileira, apresenta os jogos digitais (também nominados na BNCC como jogos eletrônicos e games) como conteúdo a ser trabalhado em diferentes etapas de ensino (Educação Infantil, Ensino Fundamental e Médio) e componentes curriculares (Língua Portuguesa, Artes e Educação Física). Para a Educação Física eles aparecem previstos nos $6^{\circ}$ e $7^{\circ}$ anos do Ensino Fundamental. Propõe-se como objetivos educacionais relacionados ao tema: "Experimentar e fruir, na escola e fora dela, jogos eletrônicos diversos, valorizando e respeitando os sentidos e significados atribuídos a eles por diferentes grupos sociais e etários"; "Identificar as transformações nas características dos jogos eletrônicos em função dos avanços das tecnologias e nas respectivas exigências corporais colocadas por esses diferentes tipos de jogos" (BRASIL, 2017, p. 230).

No documento precedente à BNCC, os Parâmetros Curriculares Nacionais (PCNs) (BRASIL, 1998), datado da década de 1990, os jogos digitais já constavam em relação ao campo de atuação educativa da Educação Física. Os videogames eram mencionados como potenciais influenciadores da cultura corporal do movimento.

Do ponto de vista da produção de conhecimento, entre 1978 e 2018, 41 artigos científicos sobre jogos digitais foram publicados em seis revistas nacionais de tradição na Educação Física brasileira. Cinco destas publicações são especificamente relacionadas à relação destes jogos com o lazer e são pesquisas que os compreendem como "[...] uma atividade alocada no campo do lazer, ou seja, como práticas inseridas em um contexto de ludicidade e de prazer" (BORSATO et al., 2019, p. 6). 
Por sua vez, Furtado et al. (2019) identificaram, em 44 periódicos de diferentes áreas, 57 artigos científicos publicados em língua portuguesa sobre jogos digitais, entre o ano de 1999 e 2017. Destes, 10 se enquadram no eixo temático Lazer e Sociedade e “[...] versam sobre as possibilidades de interpretação dos jogos eletrônicos como manifestações contemporâneas de lazer e seus possíveis desdobramentos na contemporaneidade" (FURTADO et al., 2019, p. 278), conforme classificação dos autores.

Podemos notar, portanto, a permanência e o aprofundamento dos jogos digitais como fenômeno presente nas diretrizes educacionais brasileiras para o campo da Educação Física nas últimas décadas. Não obstante, visualizamos também o crescimento da produção científica sobre o tema, bem como a abordagem dele em relação aos estudos do lazer.

Ao ser compreendido como dimensão da cultura (GOMES, 2014) e, por conseguinte, ser a expressão de aprendizagens sociais decorrentes das tramas vividas nas relações cotidianas, o lazer possui estreitas relações com a educação em seu sentido mais amplo. Isto quer dizer, que as suas práticas sociais são, ao mesmo tempo, formadas culturalmente e formadoras de cultura. É o que se chama de duplo aspecto educativo do lazer (MARCELLINO, 1987; MELO; ALVES JÚNIOR, 2003). Um aspecto, a educação para o lazer, o tem como objeto de ensino e aprendizagem e visa difundir, construir, ou ressignificar a cultura desta prática social. Outro aspecto, a educação pelo lazer, o compreende como veículo de educação e pretende "[...] aproveitar o potencial das atividades para trabalhar valores, condutas e comportamentos" (MELO; ALVES JÚNIOR, 2003, p. 53). Não é diferente com os jogos digitais, sob esta perspectiva, como expressão cultural contemporânea do lazer. A questão que se apresenta é, neste sentido, quem educa para estes jogos e o que se educa por meio destes jogos? 
Como vimos as TDICs (estando entre elas os jogos digitais), para além de serem ferramentas componentes da vida cotidiana atualmente, produziram um contexto onlife onde os nossos modos de ser, estar e compreender o mundo se modificaram (THE ONLIFE INITIATIVE, 2015). No entanto, tem se chamado atenção de que não podemos culpabilizar, unicamente, os conglomerados empresariais desenvolvedores destas tecnologias e, tampouco, responsabilizar os próprios indivíduos pelos usos e apropriações que fazem delas. Existem outras instituições, personagens e ações políticas na sociedade, tais como as famílias, as escolas, as universidades, os clubes, as associações, as políticas públicas, que constituem a trama formadora da cultura digital e, no nosso caso em específico, da cultura dos jogos digitais (BUCKINGHAM, 2012a; 2012b). Contudo, como isto ocorre nas diferentes realidades e contextos socioculturais? Quem são os participantes destes processos formativos não formais? O que se desdobra culturalmente das experiências de lazer com estes jogos?

Diante do cenário descrito até aqui, por conseguinte, optamos por abordar o fenômeno dos jogos digitais, como uma expressão de lazer do contexto onlife, sob a ótica do duplo aspecto educativo das práticas de lazer, conforme definem Marcellino (1987) e Melo e Alves Júnior (2003). Ou seja, o intuito foi observar e detalhar quem educa para este lazer e o que se educa por meio deste lazer em uma realidade específica. Desse modo, o trabalho contribui para trazer à tona detalhamentos sobre a trama social deste fenômeno cultural, que ocorre muitas das vezes na privacidade residencial e familiar, bem como nas relações privativas do universo digital. Além disso, estes dados podem subsidiar práticas educativas formais e não formais da Educação Física escolar ou da Animação Sociocultural na organização e planejamento de formações para/sobre os jogos digitais e de formações por meio dos jogos digitais. 
Como nos termos de Viana e Fortes (2011, p. 22-23), entendemos este trabalho como parte de uma demanda investigativa tanto do campo científico do lazer, como do campo da comunicação, pois "o avanço digital pelo qual o mundo passa parece criar tensão em ambos os campos, problematizando o caráter das experiências e o papel das trocas nos diferentes espaços de sociabilidade" (VIANA; FORTES, 2011, p. 22-23). Assim, o objetivo deste trabalho foi compreender por quais vias ocorre a educação para os jogos digitais e identificar expressões de aprendizagem por meio da vivência destes jogos como prática de lazer.

\section{Metodologia}

A pesquisa tem caráter exploratório e descritivo, com abordagem qualitativa (GIL, 2008). Optamos por esta perspectiva, pois tratamos de um tema em desenvolvimento que, apesar do lastro de estudos existentes, ainda está em processo de melhor compreensão, sobretudo no campo da Educação Física e dos estudos do lazer no país. Procuramos, nesse sentido, descrever o fenômeno estudado e explorá-lo a partir das falas de interlocutores estudantes de ensino fundamental de uma escola da rede pública de Campo Grande, Mato Grosso do Sul.

Os interlocutores do estudo são alunos de uma turma de $6^{\circ}$ ano do ensino fundamental, com faixa etária entre 10 e 14 anos, resultando em uma média de 11 anos de idade. Aplicamos o questionário com 21 alunos e 14 alunas. Selecionamos um grupo deste período escolar por se tratar especificamente da faixa para a qual a BNCC propõe abordar e trabalhar os jogos digitais no campo da Educação Física ( $6^{\circ}$ e $7^{\circ}$ ano). $\mathrm{O}$ questionário foi aplicado durante uma aula específica do terceiro bimestre (agosto a setembro de 2019), com perguntas abertas referentes ao conhecimento dos alunos sobre as definições e classificações dos jogos digitais, sobre a jogabilidade deles, sobre a 
maneira que jogam, sobre as primeiras experiências, sobre como são as experiências atualmente e sobre o que eles percebem e entendem que estes jogos ensinam a eles.

Esta pesquisa faz parte de projeto aprovado pelo Comitê de Ética em Pesquisa com Seres Humanos da Universidade Federal de Mato Grosso do Sul por meio do parecer 3.831.278. Para participação na pesquisa foi enviado Termo de Consentimento Livre e Esclarecido para os pais ou responsáveis pelos participantes, solicitando autorização para aplicação do questionário.

Organizamos e analisamos os dados recolhidos com base na perspectiva do duplo aspecto educativo do lazer de Marcellino (1987) e Melo e Alves Junior (2003). Portanto, no que se refere à educação para o lazer, incluímos as questões sobre as primeiras experiências, sobre quem os apresentou, bem como sobre quando e onde lhes foram apresentados os jogos digitais. Com relação à educação pelo lazer, destacamos as sensações lúdicas ${ }^{7}$ sentidas pelos interlocutores do estudo quando em interação com os jogos digitais desde as primeiras experiências até as experiências atuais, bem como elencamos os aspectos mencionados por eles como expressões de aprendizagens advindas destes jogos.

\section{Os Achados da Pesquisa}

Nesta seção do trabalho apresentamos os achados da pesquisa divididos em dois tópicos. O primeiro tópico, "Educação para os jogos digitais", corresponde aos

\footnotetext{
7 Adotamos o termo "sensações lúdicas" no sentido de buscarmos compreender também os sentimentos vividos e sentidos pelos interlocutores na relação e experiência com os jogos digitais. Nos baseamos nas ideias clássicas de Huizinga (2000) de que durante o ato de jogar/brincar os jogadores podem ir da alegria indissolúvel do jogo, até a tensão, o arrebatamento, a frivolidade e/ou o êxtase, como exemplos de pólos sentimentais humanos quando se está no ambiente do jogo/brincadeira.
} 
aspectos mediadores ${ }^{8}$ do uso destes jogos como prática de lazer. O segundo tópico, “Educação pelos jogos digitais", refere-se à mediação educativa realizada e existente por meio da utilização deles.

\section{Educação para os Jogos Digitais}

Quando questionados sobre quem os apresentou aos jogos digitais, os interlocutores do estudo citaram a família em $43 \%$ das respostas e os amigos em $20 \%$. Do total, $31 \%$ respondeu que ninguém os apresentou aos jogos e $6 \%$ não souberam dizer precisamente ou não lembravam. Em complemento a essa questão, perguntamos se nos celulares das pessoas com quem residem possuem aplicativos de jogos e $88 \%$ deles responderam positivamente.

Figura 1: Mediações Culturais das Infâncias com os Jogos Digitais

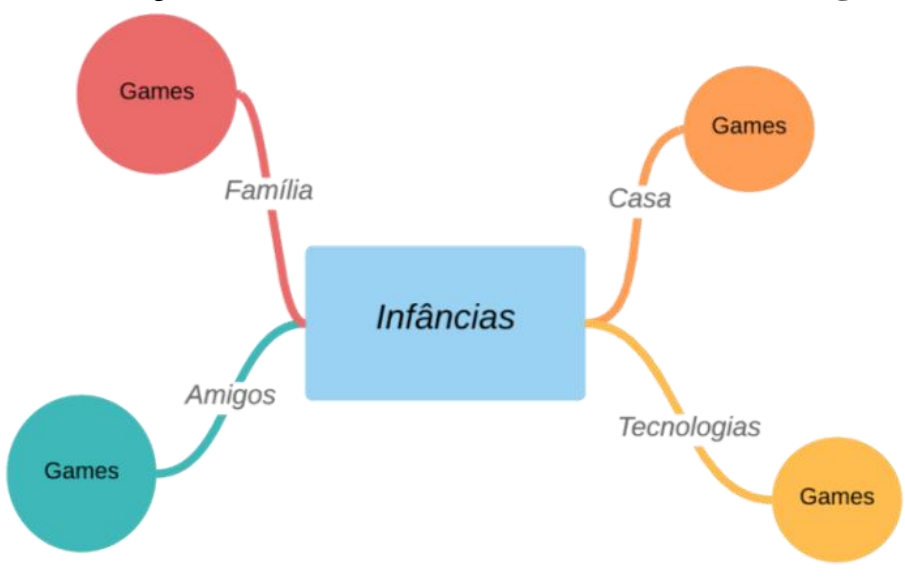

Fonte: Elaborado pelos autores

\footnotetext{
${ }^{8}$ Neste trabalho nos ancoramos na compreensão de mediações culturais da corrente latino-americana de sociologia da comunicação, sobretudo nas definições de Orozco (1993) e Martín-Barbero (2009). Portanto, nos referimos à aspectos mediadores e mediações para tratar das múltiplas dimensões socioculturais que estabelecem e manifestam qualquer tipo de comunicação e interação entre os seres humanos e o mundo vivido, e assim contribuem para a constituição e expressão dos nexos simbólicos formados no conjunto e na complexidade das relações sociais. Ou seja, tratamos as mediações culturais como aquelas ações deliberadas ou não deliberadas, com finalidades específicas ou não específicas. Por exemplo, para Orozco (1993) existe uma dialética de múltiplas mediações, que são basicamente as individuais dos próprios sujeitos (gênero, idade, história de vida), as situacionais (classe social, constituição familiar, moradia), as institucionais (escola, universidade, igrejas) e as tecnológicas (celulares, internet, redes sociais, meios de comunicação de massa). Para Martín-Barbero (2009), por sua vez, existem ao menos quatro dimensões mediadoras socioculturais, que são a institucionalidade, a tecnicidade, a ritualidade e a sociabilidade.
} 
Os primeiros dados evidenciam a relevância da mediação cultural da família e do contexto residencial no início da relação das crianças com os jogos digitais. Podemos destacar neste quesito, de um modo geral, que tendencialmente tem-se a culpabilizar o fatalismo tecnológico como o responsável pela inserção e aprofundamento das crianças no estilo de vida hiperconectado, quando, no caso do nosso estudo, embora $31 \%$ dos interlocutores tenham respondido que ninguém os apresentou aos jogos digitais, visualizamos relevante contribuição do contexto familiar para a manifestação de tal fenômeno, pois representa a maior porcentagem das respostas (43\%). Essa configuração alinha-se à ideia de que "como os pais passam cada vez menos tempo com seus filhos, eles tendem a compensar isso oferecendo bens de consumo" (BUCKINGHAM, 2012a, p. 67), sendo os jogos digitais um desses bens atualmente.

Neste ponto, a reflexão que se propõe está para além do binarismo entre a passividade ou a receptividade ativa das crianças frente às investidas de venda e consumo de bens e produtos do mercado das tecnologias e dos jogos digitais. Importanos destacar aqui, assim como Buckingham (2012a), que o tecnofetichismo e a pseudo dicotomia de consumo infantil diante dele, comumente abordada em âmbito científico, serve, na verdade, para dar suporte político às famílias e aos entes públicos na culpabilização da mídia pela introdução das crianças e jovens no universo eletrolúdico ${ }^{9}$. Essa lente de leitura encobre, em síntese, que "o mercado infantil funciona através e com a família, com o grupo de "pares" (peers) e, cada vez mais, com a escola" (BUCKINGHAM, 2012a, p. 65). O que podemos visualizar com os nossos dados,

\footnotetext{
${ }^{9}$ Apesar de não existir uma definição ou conceito fechado do termo, acompanhamos as discussões e reflexões de Cruz Junior (2013; 2017a), que propõe compreendermos o jogo digital em uma perspectiva ampliada, a qual vai além das características técnicas deste, sem negar as suas influências nas expressões lúdicas entretanto, e procura abranger a sua faceta simbólico cultural relacionada à apropriação dos sujeitos sobre estes jogos, pois múltiplas experiências culturais da ludicidade humana são produzidas, reproduzidas e recriadas nestes ambientes digitais. Assim, o termo "eletrolúdico" procura caracterizar um universo ou contexto onde ambas as dimensões, o eletrônico e o lúdico, coexistem, se auto influenciam e se auto determinam.
} 
portanto, é que o ponto de partida de construção da relação cultural dos interlocutores com os jogos digitais acontece, tendencialmente, no contexto familiar e por meio do aparato tecnológico inserido e mediado pelas famílias no ambiente residencial, mas não se restringe a isto.

Apesar de os primeiros dados demonstrarem a relevância da família na mediação cultural dos jogos digitais na vida das crianças interlocutoras do nosso estudo, por outro lado a não identificação dessa instituição social como mediadora, representada na ausência de memória de quem os apresentou a tal fenômeno de lazer $(6 \%$ dos interlocutores), é outro dado indicativo a ser destacado e refletido. Como afirmam Cruz Junior e Bungenstab (2018), a família e outras instituições como a escola e o Estado estão perdendo a hegemonia histórica na construção das identidades e sociabilidades juvenis no cotidiano contemporâneo. Nessa perspectiva, os dados do nosso estudo permitem refletir como para $37 \%$ dos interlocutores as mediações culturais da relação com os jogos digitais, ou seja, da educação para este lazer, podem ter sido realizadas por outras fontes, que não os seus próprios familiares. Tal questão pode ser interpretada, por exemplo, como decorrente da capilarização da cultura de massas por meio da ambiência digital (CRUZ JUNIOR; BUNGENSTAB, 2018; DUARTE, 2011), que ultrapassa barreiras de instituições sociais consolidadas como a família e tem permeado as infâncias. Bem como, de outro modo, essa pode ser uma expressão do protagonismo juvenil no lazer mediado por tecnologias digitais, no qual atualmente as crianças e jovens empoderam-se desde muito cedo pela formação de comunidades globais de interesses e afinidades, que ultrapassam barreiras geográficas por meio das redes (CRUZ JUNIOR; BUNGENSTAB, 2018). Independentemente da inferência a ser feita, o que constatamos com o referido dado é o grau de impessoalidade, na percepção dos interlocutores, sobre quem os educou para este lazer, os jogos digitais. 
Ainda sobre o contato inicial dos participantes do estudo com os jogos digitais, o protagonismo também mostrou-se composto pelas amizades que os circundam, uma vez que $20 \%$ das respostas mencionam os amigos. Isso significa que estes, assim como a família, se mostraram presentes na apresentação e, consequentemente, na mediação inicial dessa tecnologia digital para eles.

Além da parcela de responsabilidade no contato inicial, os amigos também aparecem como contribuintes na manutenção do contato dos interlocutores do nosso estudo com o jogo digital. Eles apareceram como principais companhias na continuidade da relação com os jogos digitais, pois $34 \%$ dos nossos participantes afirmaram jogar frequentemente com amigos e outros $34 \%$ disseram alternar entre jogar com amigos ou sozinhos. Ainda sobre as companhias dos jogadores, $14 \%$ dos interlocutores relataram jogar apenas sozinhos.

As respostas da questão anterior são coerentes com o principal tipo de jogo jogado pelos participantes do estudo. Os shooters (subcategoria dos jogos de ação), de acordo com classificação de Sato e Cardoso (2008), são jogos que as habilidades e destrezas do jogador, combinados com rápidas tomadas de decisão, são fundamentais para cumprir o principal objetivo - vencer. Eles foram maioria, com destaque para o jogo Free Fire ${ }^{10}$ mencionado 18 vezes. Esse é um tipo de jogo de Battle Royale (batalha real), que pode ser jogado tanto individualmente, como em duplas ou em equipes compostas por quatro jogadores no modo multiplayer online.

Observamos na relação com os amigos e nas possibilidades interativas proporcionadas pelos jogos digitais duas formas de mediação cultural convergentes. Nos termos de Orozco (1993), neste caso aplicado à linguagem dos jogos digitais,

\footnotetext{
10 Jogo mais baixado do mundo no ano de 2019, somando os downloads da Google Play Store e Apple Store (duas maiores lojas de jogos para smartphones). https://www.techtudo.com.br/noticias/2019/12/free-fire-foi-o-jogo-mobile-mais-baixado-em-2019-vejaranking-esports.ghtml - Acesso em: 17 abr. 2020.
} 
vemos a mediação situacional dos círculos de amizades estabelecidos pelos sujeitos como fatores determinantes da formação cultural para a referida prática de lazer, bem como visualizamos a mediação tecnológica dos jogos digitais como expressão formativa da cultura digital.

Ao retomarmos a mediação cultural da família, do ambiente residencial, e colocarmos em consonância com a mediação situacional dos círculos de amizades, os dados apresentados pelos nossos interlocutores coadunam com dados contemporâneos das práticas de lazer no Brasil. Segundo Gruber e Stoppa (2017), a casa é o principal equipamento não específico de lazer do brasileiro. Não diferente, é nesta ambiência também que a população do país mais acessa a internet para os tempos de lazer, bem como é em busca das vivências físico-esportivas e sociais, respectivamente, que mais se conecta ao universo digital com esse sentido lúdico. Portanto, as mediações familiares, domésticas e sociais identificadas nos dados, contributivas para a formação cultural dos jogos digitais como objeto e conteúdo de lazer dos entrevistados, são uma representação manifesta do contexto mais amplo deste âmbito da cultura contemporânea do país.

Com relação ao momento do primeiro contato com os jogos digitais, $31 \%$ das crianças citaram ter ocorrido entre a faixa etária de 6 a 8 anos, outros $14 \%$ mencionaram as idades de 2 a 5 anos e 54\% delas não lembravam ou não conseguiram determinar um período exato. O quadro geral indica, de tal modo, que temos um atraso relativo à Educação Física no documento norteador da educação nacional em vigência. Apesar de prevê-lo para a Educação Infantil de modo geral, a BNCC propõe a abordagem do conteúdo "jogos eletrônicos" na Educação Física para os níveis de $6^{\circ}$ e $7^{\circ}$ ano do Ensino Fundamental (idade aproximada de 10 a 12 anos).

Ao tomarmos como referência os dados encontrados neste estudo, a proposta da BNCC para a Educação Física torna-se incongruente com a realidade vivida pelas 
infâncias dos interlocutores do estudo no contexto onlife. Como visto, os participantes da pesquisa relataram ter suas primeiras experiências com jogos digitais nos primeiros anos de vida, ainda na primeira infância, pela mediação dos familiares, no interior das suas residências e pela penetração das tecnologias digitais nas suas rotinas. Diante de tal cenário, podemos definir a BNCC para a Educação Física como uma proposta restrita no que tange à abrangência etária do trabalho com os jogos digitais (SILVA et al., 2019). Uma limitação que implica em um retrato da mediação educativa formal, em específico por parte da Educação Física escolar, no processo de formação cultural para os jogos digitais como prática social e, consequentemente, como prática de lazer contemporânea. Do modo como se apresenta a questão, as crianças e jovens iniciam a interação educativa não formal para com os jogos digitais desde muito cedo e somente ao final da infância e início da adolescência o currículo escolar da Educação Física dedicar-se-á ao tema, configurando um descompasso no acompanhamento e no papel educacional da área.

De uma maneira mais ampla, Caprino e Martínez-Cerdá (2016), ressaltam que, no Brasil e na América Latina como um todo, as experiências e práticas sistematizadas de formação para e com as mídias estão mais presentes na educação não-formal do que na educação formal. Com relação ao âmbito do lazer, Stoppa et al. (2016) indicam a necessidade da formação dos profissionais deste setor se adequar às demandas socioculturais contemporâneas geradas pelas tecnologias e pela cultura digital. Nesse sentido, além de capacitar os professores de Educação Física para lidar educativamente com os games em sua atuação profissional, sobretudo no ambiente escolar, o contexto que se apresenta torna necessária uma adaptação curricular da BNCC por parte do campo da Educação Física, com vistas a promover uma antecipação temporal da mediação pedagógica da educação formal para com o fenômeno dos jogos digitais. 
Neste ponto da formalização da educação para os games como fenômeno de lazer e, portanto, como fenômeno da vida humana contemporânea, acompanhamos o entendimento de que corremos o risco de o processo educativo tornar-se irrelevante para a vida das crianças e jovens, caso não esteja aliado aos movimentos comunicativos e tecnológicos (BUCKINGHAM, 2012b). Ademais, os dados aqui apresentados reforçam a importância de um trabalho pautado nos preceitos da mídia-educação (física), de educação com, sobre e através das mídias e tecnologias (PIRES; LAZZAROTTI FILHO; LISBÔA, 2012), neste caso em específico, uma abordagem teóricometodológica que pense os jogos digitais como instrumento de educação, como objeto de estudo e como meio de criação/produção de conhecimento no universo das práticas corporais. Todavia, nos termos de Buckingham (2012b, p. 55) não podemos nos alijar de "adotar uma posição mais forte e crítica em relação à celebração da tecnologia na educação, bem como ao tipo de tecnofetichismo erroneamente considerado por alguns como a última palavra em mudança educacional".

$\mathrm{Na}$ linha das reflexões, movimentos e proposições contemporâneas de educação para as mídias, que no caso em tela propomos associá-las com a educação para os games, ou seja, a esta manifestação do lazer como finalidade educativa, os achados da pesquisa apresentados nesta seção do trabalho reiteram a candência, especialmente, por uma das propostas do Manifesto Onlife da The Onlife Initiative (2015). Em busca de melhorias políticas para promover mudanças conceituais nos modos de a sociedade se relacionar com as TDICs e, consequentemente, qualificar a governança para com elas, $o$ referido movimento preconiza a necessidade da formação de uma sociedade digitalmente competente e letrada. Para isto, os/as pesquisadores/as indicam que:

O desenvolvimento de uma relação crítica com as tecnologias não deveria tender ao estabelecimento de um espaço transcendental para além destas mediações [das TDICs], senão para uma compreensão imanente do modo em que as tecnologias nos modelam como seres humanos, ao mesmo tempo que 
nós, seres humanos, modelamos criticamente as tecnologias (THE ONLIFE INITIATIVE, 2015, p. 12).

Ao olharmos para o nosso contexto e achados sob a perspectiva do referido manifesto, visualizamos como indicativo, portanto, a premência de práticas e mediações educativas formais, em formato de políticas educacionais, na promoção de uma educação para as mídias. Perspectivamos, assim, o desenvolvimento de estratégias pedagógicas que englobem não só os estudantes, tais como os interlocutores do estudo, mas que ampliem e atraiam os personagens presentes nas relações sociais e práticas de lazer cotidianas deles, assim como as famílias e os amigos da rua, do bairro e dos ambientes digitais. Desse modo, como nos termos do manifesto, presumimos ser possível fazer uma remodelagem crítica das tecnologias e dos games coletivamente, quiçá promovendo a organização de uma sociedade baseada em competências e letramentos digitais. Uma sociedade em que as instituições formais de educação sejam percebidas como mediadoras culturais de fenômenos contemporâneos como os jogos digitais, conectando-se com a realidade vivida pelas crianças e jovens desde os seus primeiros anos de vida.

\section{Educação pelos Jogos Digitais}

Perguntados sobre como definiriam o que é jogo digital, $60 \%$ dos interlocutores do nosso estudo classificaram-no como jogo de celular, computador e/ou televisão; $14 \%$ o definiram como jogo online; $6 \%$ como aplicativo de controle do jogador; outros $6 \%$ como entretenimento; $6 \%$ também não souberam defini-lo. Ainda sobre a definição do jogo, uma resposta definiu como jogar com as mãos; outra como coordenação; outra como jogo que não pode ser tocado; outra como jogo que é possível digitar; e, finalmente, uma outra definiu como jogo tecnológico. As respostas transmitem, em um 
primeiro olhar, definições baseadas no instrumento utilizado, no espaço/ambiência onde jogam, ou naquilo que o jogo representa para eles, como entretenimento.

De acordo com Cruz Júnior (2017a), os jogos digitais são compostos dos mesmos pretextos que o jogo, porém diferem na maneira com que essas características se apresentam durante a execução deste. O celular, o computador ou a televisão, nos termos do autor, podem ser classificados como instrumentos que possibilitam o jogar, mas não como definição do fenômeno.

Os dados apresentados nos permitem inferir, mais uma vez, a ausência da mediação educativa formal no trato e no relacionamento com os jogos digitais. Mesmo imersos na cultura dos jogos digitais desde as fases iniciais da vida, como visto anteriormente, a dificuldade em definir os jogos digitais é um primeiro indício ou sintoma da informalidade e, consequentemente, da inconsistência do que se aprende sobre os jogos digitais por meio da vivência e da experiência com eles próprios nos tempos e espaços de lazer da infância. Essa, por exemplo, é uma lacuna passível de ser ocupada pela Educação Física escolar no sentido de contribuir com uma compreensão ampla, crítica e esclarecedora de um fenômeno que os constituem como seres sociais na contemporaneidade e que compõe o universo lúdico, simbólico e imaginário das suas experiências de brincar/jogar. É possível, assim, empoderá-los na relação com os jogos digitais, como na perspectiva de Melo e Alves Junior (2003) sobre Educação e Lazer, de modo a otimizarem, ampliarem e se emanciparem acerca das possibilidades de vivência do lazer digital como momento de ócio.

Ao serem questionadas sobre o que percebem aprender com os jogos digitais, $34 \%$ das crianças responderam que não aprendem nada, o que aparenta manifestar o caráter desinteressado dessa experiência lúdica por parte dos jogadores e observadores, como nos termos de Huizinga (2000). Sob essa ótica podemos compreender que mesmo 
cercados por valores, sentimentos e experiências, muitas vezes os ensinamentos e aprendizados proporcionados pelos jogos digitais podem não ser objetivamente percebidos pelos próprios jogadores.

Como afirma Fantin (2015), o indicativo negativo de aprendizagem com relação aos jogos, brincadeiras e jogos digitais por parte das crianças é recorrente em pesquisas com esse enfoque. Segundo a autora, para alcançar as aprendizagens, metodologicamente é preciso ir além dos questionamentos para as crianças em entrevistas e questionários, e observar a prática delas nos diferentes contextos em que estabelecem relação com os fenômenos lúdicos. Esse, portanto, é um relevante limite metodológico da presente investigação a ser explorado em futuros estudos.

Apesar da limitação investigativa identificada, podemos associar que o caráter desinteressado das crianças para com os games representa a expressão desse fenômeno no tempo e no espaço de lazer como dimensão da cultura contemporânea. Esta representação dos jogos digitais, olhada pelos termos de Gomes (2014), configura-o como fenômeno componente das experiências vividas pelos sujeitos com fim em si mesmas e, ao menos a priori, sem objetivos outros.

Por outro lado, em $11 \%$ das respostas as crianças mencionaram aprender a atirar e a matar com os jogos digitais. Apesar de esse fato, de maneira imediata, nos remeter a uma ideia de violência, não é possível afirmar que essas experiências automaticamente conduzem-nas a atitudes do tipo.

Estudos indicam, de um modo geral, que não há relação direta de causa e consequência, de a violência representada nos jogos digitais formar ou motivar sujeitos para o exercício de práticas sociais efetivamente violentas. Observa-se, pelo contrário, que tais expressões lúdicas são formas de catarse, ou ferramentas de escape para as pulsões de agressividade humana, conformando-se como um mecanismo 
contemporâneo de busca da excitação (REIS; CAVICHIOLLI, 2008). Ademais, quando práticas sociais de violência são expressas em atitudes de jogadores, seja no contexto do game ou fora dele, elas são oriundas das trajetórias de vida de um modo mais amplo, não se restringindo aos jogos digitais (RETONDAR; BONNET; HARRIS, 2016).

Em observância à insurgência de menções sobre práticas sociais de violência, o dado sugere que além de proporcionar diferentes experiências e fruições de jogos digitais, como previsto na BNCC, podemos depreender a necessidade de a mediação educativa das aprendizagens advindas destes jogos também se referir à aspectos civilizatórios das relações sociais na formação cultural das crianças e jovens. Sabemos que é possível vivenciar jogos digitais sem necessariamente precisar atirar ou matar na vida cotidiana. Tal situação reforça tanto a ideia de que "os videogames não são objetos neutros, inofensivos e que eles tendem a refletir e a reforçar valores da sociedade em que vivemos" (AMARAL; PAULA, 2007, p. 158-159), como reitera a carência da abordagem pedagógica dos jogos digitais na educação e na Educação Física formal (AMARAL; PAULA, 2007).

Além da suposta dimensão violenta, outros aprendizados foram destacados pelos interlocutores do estudo, tais como: Raciocínio em 8,5\% das respostas; sobrevivência em 5,7\% e montar; desenhar; criar; trabalho em equipe; estratégia; responsabilidade; e compreensão do idioma inglês em 2,8\%. Os dados retratam manifestações (verbais ou escritas) associadas a eventuais possibilidades de aprendizagens com os jogos digitais por meio dessa prática de lazer. Nesse sentido, as instituições de educação formal (escola e a EF escolar) e informal (família em contexto residencial), tão qual os animadores socioculturais (no lazer), podem se utilizar destas manifestações para criar ambientes de aprendizagens e mediar, educativamente, as experiências já vividas com os jogos digitais. 
No tocante à educação formal, como a BNCC contém o conteúdo de jogos digitais em mais áreas do conhecimento além da Educação Física, inseridos nas competências de Linguagens e Artes, e os interlocutores relatam aprendizados como raciocínio, desenhar e compreender outro idioma abre-se a possibilidade de planejamento e construção de um trabalho multidisciplinar com o tema. Todavia, reforçamos que a Educação Física pode se posicionar no protagonismo das ações, uma vez que historicamente é a área que se debruça nos estudos do lazer, sem desmerecer os demais campos que também o estudam.

\section{Figura 2: Eventuais aprendizados relatados pelas crianças por meio dos Jogos Digitais}

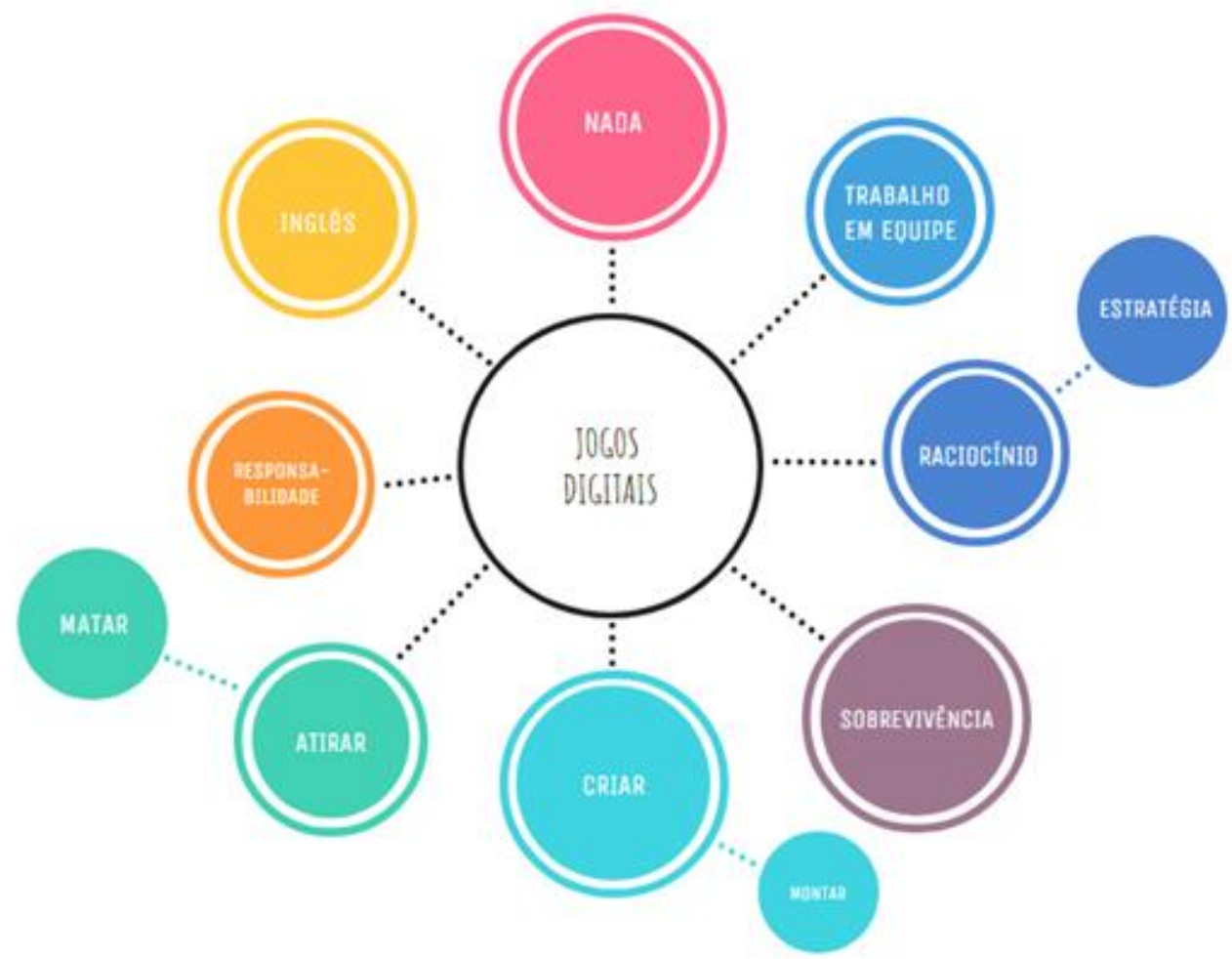

Fonte: Elaborado pelos autores

No tocante às sensações proporcionadas pela vivência dos jogos digitais, a diversão esteve presente em $37 \%$ das respostas. $23 \%$ citaram a felicidade como sensação. $14 \%$ relataram satisfação e outros $14 \%$ animação. O estresse também esteve presente em $11 \%$ das respostas. Calma, curiosidade, pertencimento, medo, vício e competição também foram ocorrências nas respostas. 
Os dados reforçam, desse modo, o quão candente é a necessidade de compreendermos os jogos digitais não exclusivamente como um instrumento tecnológico ou educacional, mas também como objeto a ser estudado e como via de produção de diferentes e contemporâneas expressões culturais do âmbito do lazer. Neles os/as jogadores/as riem, se animam, ficam felizes, com medo, tensos, curiosos, nada tão diferente de como dissertou Huizinga (2000), em suas descrições clássicas sobre a ludicidade humana no brincar/jogar como campo de expressão de múltiplas sensações.

Gee (2009) ressalta, a partir de observações e reflexões, como elementos da linguagem dos jogos (digitais) configuram, de um modo geral, aspectos passíveis de serem apropriados para o desenvolvimento de boas aprendizagens, assim como a possibilidade de construção e reconstrução de identidades, a interatividade, a demanda por resoluções de problemas em diferentes contextos, o desenvolvimento de pensamentos sistemáticos, as frustrações prazerosas, entre outros. São aprendizados, de acordo com o autor, vinculados às experiências a serem comumente vividas no mundo.

A mescla de sensações lúdicas mencionadas pelos interlocutores do nosso estudo como advindas da vivência dos games são empiria que reitera as ideias clássicas de Huizinga (2000) sobre a ampla gama de sentimentos gerados pelo jogar/brincar, bem como algumas ideias contemporâneas de Gee (2009) sobre a relevância das frustrações prazerosas dos jogos digitais no desenvolvimento de boas aprendizagens. Contudo, mais do que reforçar teorias e estudos anteriores, estes dados também são pistas para melhor compreendermos, por exemplo, o que se experimenta e o que se vive neste contexto onlife. As felicidades, animações, tensões, entre outros sentimentos observados na pesquisa, são expressões da relação subjetiva que cada um dos sujeitos estabelece com o fenômeno dos jogos digitais. Portanto, se configuram como elementos indiciários de como estes interlocutores lidam com a transitoriedade e o entrecruzamento das 
inexistentes ou fluidas fronteiras do real e do virtual, do online e do offline, tal como destacado pela The Onlife Initiative (2015) no prognóstico da sociedade hiperconectada.

Ao seguir uma perspectiva freireana de alfabetização e letramento de educação para e com os jogos digitais, Cruz Junior (2017b, p. 229-230) disserta:

\begin{abstract}
Enquanto ramificação da língua-mundo, os jogos (digitais) compõem um domínio semântico que demanda alfabetização e letramentos próprios, posto que apresenta estruturas singulares de decodificação e produção de significados. Nesse sentido, não está em causa apenas uma habilidade restrita aos jogos propriamente ditos, mas à vida em sua totalidade, posto que essa, como vimos, é cada vez mais nutrida por atributos típicos do brincar. Ademais, não convém entender a presença generalizada dos jogos de modo essencialista e maniqueísta, classificá-la como inerentemente boa ou ruim, já que nela cabe toda a sorte de interesses, usos e apropriações. Ao negar aos sujeitos a autonomia e os conhecimentos necessários para vivenciar as experiências que se caracterizam como jogos (ou que apenas se inspiram neles), o analfabetismo eletrolúdico converte-se numa problemática digna de preocupação e, por consequência, num potencial alvo de ações afirmativas, sobretudo por parte do campo educacional.
\end{abstract}

O repertório de sensações experimentadas pelas crianças interlocutoras do nosso estudo, olhadas sob a perspectiva de Gee (2009) e Cruz Junior (2017b), revela a insurgência de um potencial caminho de formação e atuação para o campo da Educação Física e do Lazer. Os jogos digitais como fenômeno dos tempos e espaços socioculturais das crianças, por esse entendimento, mostram-se como importantes vias de aproximação dialógica, para essas áreas de atuação educacional, com os modos de ser, estar e fruir das crianças hoje. Compreendermos e observarmos a gama de expressões de aprendizagens e sensações lúdicas explicitadas no presente estudo significa, em primeiro lugar, reconhecer que há ali saberes construídos pelos jogadores a serem considerados como ensinamentos destas experiências de lazer. Em segundo lugar, são estes ensinamentos os códigos dos jogos digitais como língua-mundo, como mencionado por Cruz Junior (2017b), a serem decodificados nos processos de mediação educativa formal ou informal, na escola ou na animação sociocultural, no contexto familiar, residencial, ou qualquer outro, de modo a evitarmos o analfabetismo eletrolúdico funcional. 
O que destacamos nesta seção do trabalho, baseados nos achados do estudo, é o relevante papel de mediação cultural a ser exercido pela Educação Física na garantia da autonomia dos seres sociais para a vivência, experimentação e reflexão dos diferentes usos, apropriações e interesses possíveis de serem manifestos na relação com o fenômeno de lazer abordado nesta pesquisa, os jogos digitais. Visualizamos na conjugação da múltipla gama de aprendizados com a multissensorialidade lúdica das experiências com os jogos digitais, conforme ressaltado pelos nossos interlocutores, a possibilidade, por exemplo, de proteção das nossas capacidades atencionais no contexto onlife.

Em consonância com os termos do Manifesto Onlife (THE ONLIFE INITIATIVE, 2015), vivemos um momento de inflação da produção e circulação de conteúdos e informações digitais, que concorrem, comercializam e buscam monopolizar a capacidade e o tempo de atenção da sociedade. Os jogos digitais, por sua vez, são uma das diversas expressões deste fenômeno. Crianças e jovens entregam horas dos seus dias para estes jogos ao redor do mundo. Para o grupo de pesquisadores/as, um dos princípios base para resistirmos e subvertermos a tal contexto é preservarmos as nossas capacidades de atenção diante dessas produções da infoesfera (THE ONLIFE INITIATIVE, 2015). Neste sentido e mediante os achados do estudo, perspectivamos a Educação Física como tempo e espaço profícuo para lograr tal êxito de preservação atencional na mediação cultural destes lazeres, os jogos digitais. Ou seja, por meio da sua atuação na educação formal e não-formal, no campo escolar, universitário ou na animação sociocultural, ao unir a multiplicidade de aprendizagens dos jogos digitais com procedimentos mídia-educativos críticos e criativos (FANTIN, 2006; PIRES; LAZZAROTI FILHO; LISBÔA, 2012), a Educação Física pode vir a produzir e promover práticas profissionais e educativas emancipatórias, contributivas para a 
preservação consciente das capacidades e direitos humanos de focalizar a própria atenção como "[...] condições fundamentais e indispensáveis para a autonomia, responsabilidade, reflexão, pluralidade, compromisso e busca de sentido" (THE ONLIFE INITIATIVE, 2015, p. 12-13), seja na vida hiperconectada de modo mais amplo, seja nas vivências dos tempos e espaços de lazer.

\section{Considerações Finais}

De um modo geral, o presente estudo contribui para melhor compreendermos as relações sociais mediadoras do estabelecimento dos jogos digitais como fenômeno cultural das vivências dos tempos e espaços de lazer de crianças e jovens. Identificamos a participação da mediação familiar e domiciliar no princípio da educação para os jogos digitais. Encontramos também a mediação dos círculos de amizades e das tecnologias no início desse processo, mas, sobretudo na continuidade dele. Neste ponto, portanto, chamamos atenção para a ausência da escola e da Educação Física como instituições e ambiências mediadoras da introdução e permanência no universo lúdico digital, de acordo com a percepção dos interlocutores do estudo.

A escola é um espaço prevalente do tempo vivido das crianças e jovens, principalmente com o advento do modelo de tempo integral. A Educação Física, por sua vez, é o componente curricular historicamente vinculado ao jogar/brincar como fenômeno da cultura corporal de movimento a ser experimentado no contexto escolar. Ao se ausentarem ou se atrasarem na mediação dos jogos digitais como expressão lúdica contemporânea, a escola e a Educação Física acabam responsabilizando, unicamente, as famílias e deixam espaços livres para a atuação do mercado neste processo educativo. 
Ora, se o lazer é um direito social ${ }^{11}$ previsto constitucionalmente no Brasil e os jogos digitais são uma expressão contemporânea dessa prática social, é também papel do Estado promover tal mediação. Seja por meio da escola, das políticas públicas de animação sociocultural e pela regulação do mercado dos jogos digitais, deve-se não só expandir e democratizar o acesso a eles nos tempos e espaços das crianças e jovens, mas possibilitar que elas exerçam, também por essa via, a cidadania digital. Pode-se operacionalizar isso estabelecendo parâmetros éticos e normas para a atuação do mercado, de modo que sejam respeitados os direitos da criança e do adolescente. São necessárias adaptações infraestruturais das escolas para que comportem, por exemplo, conectividade qualificada com os jogos digitais. Deve-se também promover cursos de formação continuada para professores e educadores sociais do campo do lazer no sentido de que estejam capacitados e atualizados para o desenvolvimento de uma educação com, sobre e através das práticas eletrolúdicas.

Além da dimensão dos espaços sociais promotores e mantenedores deste fenômeno de lazer para as crianças e jovens, visualizamos também a questão temporal como necessária de ser observada e pensada do ponto de vista educacional. Os dados da pesquisa revelam um envolvimento cada vez mais prematuro com o contexto lúdico dos jogos digitais, enquanto a proposição mais atual da educação brasileira prevê uma mediação formal da Educação Física somente para a partir dos 11 anos de idade, no período do $6^{\circ}$ e $7^{\circ}$ ano do ensino fundamental. Ainda que não se possa desconsiderar a tematização dos jogos digitais na etapa da Educação Infantil, como consta na BNCC, entendemos que também não se pode deixar de reconhecer o protagonismo e a contribuição do campo da Educação Física para os estudos sobre o brincar e o lazer nas

\footnotetext{
${ }^{11}$ Art. $6^{\circ}$ da Constituição Federal de 1988 (BRASIL, 1988), (Redação dada pela Emenda Constitucional no 90, de 2015): "São direitos sociais a educação, a saúde, a alimentação, o trabalho, a moradia, o transporte, o lazer, a segurança, a previdência social, a proteção à maternidade e à infância, a assistência aos desamparados, na forma desta Constituição".
} 
infâncias. Por conta disso, reforçamos entender como importante uma possível antecipação do tema para o campo específico da Educação Física escolar na proposta curricular nacional. Adicionalmente, destacamos a necessidade de se pensar e refletir o que retirar dos conteúdos e temas das séries iniciais para incluir os jogos digitais? O excesso de conteúdos, sobretudo nas primeiras fases da educação escolar, é um dos reclames e críticas contemporâneas mais incisivas hoje. Então, o que fazer? Como abrir espaço para um tema candente na atualidade sem desmerecer, ocultar ou até excluir os demais? São questões a serem pensadas, consideradas e melhor estudadas em futuras investigações e discussões do campo.

Para fazer sentido na formação de crianças e jovens, a educação formal deve estar conectada às dinâmicas sociais, culturais e tecnológicas. Caso contrário, corre o risco de tornar-se obsoleta, dispensável. Todavia, tal conexão com a realidade não se trata de uma proposição pedagógica tecnofetichista, como citado anteriormente. Referimo-nos, em síntese, a uma política e um currículo educacionais que se antecipem aos problemas e questões insurgentes das dinâmicas socioculturais do tempo vivido, em especial das infâncias experienciadas na sociedade onlife. Tratamos, aqui, de uma educação e uma Educação Física que abordem os jogos digitais em uma perspectiva mídia-educativa, trabalhando-os, sobretudo como objeto de estudo e como via criativa de produção de conhecimento.

Ao ocuparem tempos e espaços em experiências de lazer de crianças, jovens e adultos, os jogos digitais revelam-se incorporados na cultura contemporânea. Diante da complexidade do mapa que ilustra essa configuração, cartografado por mediações e mutações culturais múltiplas e por se tratar de uma investigação pontual, realizada por meio de um questionário com perguntas pré-definidas, os procedimentos metodológicos de produção dos dados da presente pesquisa revelaram-se limitados para alcançar 
reflexões sobre a realidade dos interlocutores da pesquisa. Isto se evidenciou, principalmente, no que tange à realidade socioeconômica, condição de acesso às TDICs e como são os usos destas tecnologias. Também ficaram carentes neste questionário as expressões de aprendizagem da prática dos jogos digitais. Além disso, conforme exposto nos dados do estudo, o contato com os jogos é evidente desde a primeira infância em alguns casos, desse modo, um estudo voltado apenas aos níveis de ensino em que os jogos digitais aparecem na BNCC também se configura limitado, pois deixa de explorar as sensações e aprendizagens desenvolvidas nas demais faixas etárias da infância e adolescência.

Sugerimos, finalmente, o desenvolvimento de estudos em perspectivas socioantropológicas da comunicação, inspirados em procedimentos etnográficos e/ou em estratégias de pesquisa-ação nos diversos níveis da Educação Básica. Pesquisas que produzam conhecimentos densamente descritos sobre o perfil sociodemográfico dos interlocutores, a relação infanto-juvenil com os jogos digitais, e que também promovam experiências com o amplo espectro de sensações e vivências lúdicas proporcionadas por esse fenômeno, de um modo tal que esteja cada vez mais clara a sua contribuição educativa para a leitura do mundo presente.

\section{REFERÊNCIAS}

AMARAL, S.C.F.; PAULA, G.N. de. A nova forma de pensar o jogo, seus valores e suas possibilidades. Pensar a Prática, v. 10, n. 2, p. 155-168, 2007.

BORSATO, M.; BRASIL, M.R.; OLIVEIRA, V.M. de.; MATTES V.V.; SOUZA, J. de. Produção acadêmico-científica sobre os jogos eletrônicos em periódicos da área de Educação Física no Brasil. Motrivivência, Florianópolis/SC, v. 31, n. 60, p. 01-23, 2019.

BRASIL. Constituição, 1988. Constituição da República Federativa do Brasil. Brasília: Senado Federal: Centro Gráfico, 1988. 
BRASIL. Parâmetros Curriculares Nacionais: Educação Física. Brasília: Secretaria de Educação Fundamental, MEC/SEF, 1998. 2017.

Ministério da Educação. Base Nacional Comum Curricular. Brasília: MEC,

BUCKINGHAM, D. Repensando a Criança-consumidora: Novas Práticas, Novos Paradigmas. Comunicação Mídia e Consumo, v. 9, n. 25, p. 43-72, 2012a.

Precisamos realmente de educação para os meios? Comunicação e Educação, v. 17, n. 2, p. 41-60, 2012 b.

CAMARGO, L.O. L. Educação para o lazer. São Paulo: Moderna, 1998.

CAPRINO, M.P.; MARTÍNEZ-CERDÁ, J.F. Media Literacy in Brazil: Experiences and Models in Non-formal Education Alfabetización mediática en Brasil: experiencias y modelos en educación no formal. Comunicar, v. 24, n. 49, p. 39-48, 2016.

COSTA, A.Q. da. Jogos digitais e Educação Física: por uma experiência corporal educativa. In: ARAÚJO, A.C. de; SANTOS, A. de P. dos; DIAS, M.A.; MENDES, M.I.B. de S.; MELO, J.P. de. Diálogo entre Educação Física e Comunicação: compartilhando saberes e práticas. Natal/RN: EDUFRN, p. 53-81, 2016.

; BETTI, M. Mídias e jogos: do virtual para uma experiência corporal educativa. Revista Brasileira de Ciências do Esporte, v. 27, n. 2, p. 165-178, 2006.

CRUZ JUNIOR, G. Jogando na Era da Convergência: Notas sobre a produção eletrolúdica no ciberespaço. Licere, Belo Horizonte, v.16, n.4, p. 1-25, 2013. DOI: https://doi.org/10.35699/1981-3171.2013.669

delinquente em cada um de nós: uma introdução à pedagogia do "mau exemplo" nos videogames. Curitiba: CRV, 2017a.

Vivendo o jogo ou jogando a vida? Notas sobre jogos (digitais) e educação em meio à cultura ludificada. Revista Brasileira de Ciências do Esporte, v. 39, n. 3, p. 226-232, 2017b.

Temos que pegar? Pokémon Go e as interfaces entre movimento, jogos digitais e educação. Motrivivência, Florianópolis/SC, v. 29, n. esp., p. 257-273, 2017 c.

; BUNGENSTAB, G.C. Entre o tempo livre e a educação: Considerações sobre juventude, mídias e lazer. Licere, Belo Horizonte/MG, v. 21, n. 4, p. 502-528, 2018. DOI: http://doi.org/10.35699/1981-3171.2018.1951.

DUARTE, R. Indústria Cultural 2.0. Revista De Teoría Crítica, v. 3, n. 3, p. 90-117, 2011.

DUMAZEDIER, J. Sociologia Empírica do Lazer. São Paulo: Perspectiva, 1979.

FANTIN, M. Mídia-educação: olhares e experiências no Brasil e na Itália. Florianópolis: Cidade Futura, 2006. 
FANTIN, M. Crianças e games na escola: entre paisagens e práticas. Revista Latinoamericana de Ciências Sociales, Niñez y Juventud, v. 13, n. 1, p. 195-208, 2015.

FERNANDES, B.P.F.; MARTINS, I.C.; SOUZA, A.S.; DA SILVA, C.L. Entre o tradicional e o eletrônico: significados do brincar para crianças de uma escola pública de Piracicaba - SP. Revista Brasileira de Estudos do Lazer. Belo Horizonte, v. 3, n. 2, p.74-96, 2016.

FURTADO, H. L.; CORRÊA, C.; CANI, M.; MORAES E SILVA, M. Análise da produção científica sobre jogos eletrônicos disponíveis nos portais SciELO, Lilacs e portal de periódicos da CAPES. Licere, Belo Horizonte, v. 22, n. 4, p. 260-284, 2019. DOI: https://doi.org/10.35699/1981-3171.2019.16268

GEE, J.P. Bons videogames e boa aprendizagem. Perspectiva, v. 27, n. 1, p. 167-178, 2009.

GIL, A.C. Métodos e técnicas de pesquisa social. 6. ed. Editora Atlas SA, 2008.

GOMES, C.L. Lazer: necessidade humana e dimensão da cultura. Revista Brasileira de Estudos do Lazer, v. 1, n. 1, p. 3-20, 2014.

GRUBER, G.V.; STOPPA, E.A. O lazer do brasileiro: representações e concretizações nos espaços e equipamentos. In: STOPPA, E. A.; ISAYAMA, H. T. (org.). O lazer no Brasil - representações e concretizações das vivências cotidianas. Campinas: Autores Associados, 2017. p. 81-94.

HUIZINGA, J. Homo Ludens. 4. ed. São Paulo: Editora Perspectiva S.A., 2000.

MARTÍN-BARBERO, J. Dos meios às mediações: comunicação, cultura e hegemonia. 6. ed. Rio de Janeiro: Editora UFRJ, 2009.

MIRANDA, L.T. de; FANTIN, M. A perspectiva social das competências midiáticas: reflexões sobre participação e interação das crianças na escola. Lumina, v. 12, n. 1, p. 55-67, 2018.

MARCELLINO, N.C. Lazer e educação. Campinas: Papirus, 1987.

MELO, V.A. de; ALVES JUNIOR, E.D. Animação Cultural: conceitos In: MELO, V.A. de; ALVES JUNIOR, E.D. Introdução ao Lazer. Barueri: Manole, 2003. p. 5173.

MENDES, D. DE S.; PIRES, G. D. L. Desvendando a janela de vidro: relato de uma experiência escolar de mídia-educação e Educação Física. Revista Brasileira de Ciências do Esporte, v. 30, n. 3, p. 79-94, 2009.

OROZCO, G.G. Hacia una dialéctica de la recepción televisiva: la estructuración de estrategias por los televidentes. Comunicação \& Política na América Latina, São Paulo, ano 8, v. 22 a 25, p. 57-73, 1993.

PIRES, G.L.; LAZZAROTTI FILHO, A.; LISBÔA, M.M. Educação Física, mídia e tecnologias: incursões, pesquisa e perspectivas. Kinesis, v. 30, n. 1, p. 55-79, 2012. 
REIS, L.J.A.; CAVICHIOLLI, F.R. Jogos Eletrônicos e a Busca da Excitação. Movimento. Porto Alegre, v. 14, n. 03, p. 163-183, 2008.

RETONDAR, J.J.M.; BONNET, J.C.; HARRIS, E.R.A. Jogos eletrônicos: corporeidade, violência e compulsividade. Revista Brasileira de Ciências do Esporte. v. 38, n. 1, p. 3-10, 2016.

RINCÓN, O. Mutações bastardas da comunicação. Matrizes, v. 12, n. 1, p. 65-78, 2018.

Mapa Insomne 2017: ensayos sobre el sensorium contemporáneo. Un mapa para investigar la mutación cultural. In: JACKS, N.; SCHMITZ, D.; WOTTRICH, L. Um nuevo mapa para investigar la mutación cultural: diálogo com la propuesta de Jesús Martín-Barbero. Quito: Ediciones Ciespal, p. 17-24, 2019.

SATO, A.K.O.; CARDOSO, M.V. Além do gênero: uma possibilidade para a classificação de jogos. In: BRAZILIAN SYMPOSIUM ON COMPUTER GAMES AND DIGITAL ENTERTAINMENT, 7, 2008. Anais...p. 54-63, 2008.

SCHWARTZ, G.M. O conteúdo virtual do lazer: Contemporizando Dumazedier. Licere, Belo Horizonte. v. 6, n. 2, p. 22-31, 2003.

SILVA, L.B.; LOURENÇO, O.B.; MONTEIRO, V.A.N.; DOS SANTOS, S.M. Jogos Eletrônicos na Educação Física Escolar: Uma Análise da Base Nacional Comum Curricular (BNCC). REUNIÃO ANUAL DA SBPC - 21 A 27 DE JULHO DE 2019, 71, 2019. Anais... Campo Grande-MS, 2019.

SILVA, L.B.; LOURENÇO, O.B.; MONTEIRO, V.A.N.; SILVA, J.V.P; DOS SANTOS, S.M. Remixando jogos digitais na escola: uma experiência corporal, algumas análises e reflexões possíveis. Motrivivência, v. 32, n. 63, p. 1-21, 2020.

SOUZA JUNIOR, A.F. de; LISBOA, T.F.M.; COSTA, A.Q. da. Gamificação e Educação Física Escolar: debatendo conceitos e compartilhando possibilidades. In: ARAÚJO, A. de C.; OLIVEIRA, M.R.R. de; SOUZA JUNIOR, A.F. de. Formação continuada em Educação Física no diálogo com a cultura digital. João Pessoa: IFPB, 2019. p. 91-113.

STOPPA, E.A.; DE PAULA, J.N.; DE MORAES, I.A.P.; BONIFÁCIO, D.C. Lúdico e jogos digitais: reflexões acerca da formação e atuação profissional. Revista Brasileira de Estudos do Lazer. Belo Horizonte, v. 3, n. 2, p.113-128, 2016.

THE ONLIFE INITIATIVE. The onlife manifesto. In: FLORIDI, Luciano (ed.). The Onlife Manifesto: Being Human in a Hyperconnected Era. Oxford: Springer Open, p. 7-16, 2015.

VIANA, J.A.; FORTES, R. Do lazer e da comunicação: relações em campo(s). Licere, Belo Horizonte, v. 14, n. 3, 2011. DOI: https://doi.org/10.35699/1981-3171.2011.763

WIGGERS, I.D.; OLIVEIRA, M.S. DE; FERREIRA, I.V. Infância e educação do corpo: as mídias diante das brincadeiras tradicionais. In: INEP. Em Aberto. Inep/MEC - Instituto Nacional de Estudos e Pesquisas Educacionais Anísio Teixeira, Brasília/DF. v. 31, n. 102, p. 177-190, 2018. 


\section{Endereço dos Autores:}

Vinicius Augusto do Nascimento Monteiro

Endereço eletrônico: vanm.vinicius@gmail.com

Silvan Menezes dos Santos

Endereço eletrônico: bammenezes90@gmail.com 